\title{
Retinopathy of prematurity: systemic complications associated with different anaesthetic techniques at treatment
}

\author{
Paul M Haigh, Malcolm L Chiswick, Eamonn P O’Donoghue
}

\begin{abstract}
Background-Treatment of retinopathy of prematurity (ROP) in the UK is subject to considerable regional variation in terms of anaesthetic support. Change in practice at St Mary's neonatal medical unit from topical to general anaesthesia and, subsequently, to sedation/analgesia allowed comparison of the impact of these three modalities on infants' early postoperative course in a consecutive, non-randomised, observational study.
\end{abstract}

Methods-The study population consisted of 30 babies undergoing treatment of threshold ROP. Twelve were treated using topical anaesthesia alone (group A), six using general anaesthesia (group B), and 12 using sedation/analgesia combined with elective intubation and artificial ventilation (group C). Daily measurements of infant health were recorded starting 4 days preoperatively and continuing for 7 days postoperatively to facilitate the formulation of a cardiorespiratory stability index as follows: (0) improvement from baseline, (1) no change from baseline, (2) mild instability, (3) marked instability, and (4) life threatening event.

Results-Within the first 48 hours postoperatively in group A 5/12 showed mild instability and $4 / 12$ showed marked instability (including three babies suffering life threatening events requiring emergency resuscitation). In group $B$ within the first 48 hours postoperatively $1 / 6$ showed mild and 1/6 showed marked instability, and in group C 5/12 babies showed mild instability alone. There was a significant difference for cardiorespiratory stability scores between the three groups overall for the 7 days postoperatively (repeated measures ANOVA, $\mathrm{p}=0.018$ ).

Conclusions-Premature infants undergoing cryotherapy for ROP who were treated using topical anaesthesia alone had more severe and protracted cardiorespiratory complications.

(Br F Ophthalmol 1997;81:283-287)

It is now well recognised that neonates and infants perceive pain ${ }^{12}$ and that they mount a substantial stress response to painful stimuli. ${ }^{3-5}$ Premature infants tend to be more unstable systemically than full term infants of the same postnatal age, and are more susceptible to episodes of apnoea and bradycardia. ${ }^{6}$ Further- more, the oculocardiac reflex is well developed in infants, ${ }^{8}$ and this, together with their increased cardiorespiratory instability, makes preterm infants especially vulnerable when undergoing treatment for retinopathy of prematurity (ROP). Significant systemic complications occurring during and after ROP treatment have been reported ${ }^{9-11}$ but, to date, little has been published to indicate which anaesthetic technique provides optimum conditions for these high risk babies.

In the UK there is wide variation in the type of anaesthesia used for the treatment of ROP. A recent nationwide study, ${ }^{12}$ which targeted 118 neonatal units, found that $23 \%$ of units are using topical anaesthesia alone, $57 \%$ are using general anaesthesia, and $20 \%$ are using a combination of modalities.

At Manchester Royal Eye and St Mary's hospitals there had been a change in practice, prompted by concern regarding infant stress and risk of systemic complications, from using topical anaesthesia alone to using general anaesthesia and subsequently sedation/ analgesia. This allowed a consecutive, nonrandomised, observational study comparing the impact of these different anaesthetic techniques on the systemic stability of babies receiving treatment for ROP.

\section{Methods}

All babies undergoing retinal ablative treatment of threshold ROP over a 2 year 8 month period to 1994 (when laser superseded cryotherapy) were included in the study. The total study population could be divided into three groups (A, B, or C) according to the modality of anaesthesia used for treatment. Group A consisted of babies treated using topical anaesthesia alone, group B babies treated using full inhalational general anaesthesia, and group C babies treated using sedation/analgesia. The details of the anaesthetic techniques used for the three groups are given in Table 1. All babies underwent cryotherapy without conjunctival incision using a Schulenburg cryoprobe, all treatments were carried out by the same surgeon (EO'D), and all babies received steroid/antibiotic drops (for 2 weeks) and cycloplegic drops (for 1 week) to the treated eyes. The Cryo-ROP study criteria for threshold disease were fulfilled by all subjects, all of whom had zone 2 involvement. Data were collected from the neonatal medical unit (NMU) records and prospectively evaluated using standard proforma. 
Table 1 Study population $(n=30)$

\begin{tabular}{lll}
\hline Group & Anaesthetic technique & $\begin{array}{l}\text { Treatment site and doctor } \\
\text { responsible for giving anaesthetic }\end{array}$ \\
\hline $\mathrm{A}(\mathrm{n}=12)$ & Topical amethocaine & $\begin{array}{l}\text { Operating theatre, paediatric } \\
\text { anaesthetist }\end{array}$ \\
$\mathrm{B}(\mathrm{n}=6)$ & $\begin{array}{l}\mathrm{N}_{2} \mathrm{O} / \mathrm{O}_{2} \text {, halothane, muscle relaxation, } \\
\text { and intubation } \\
\text { Operating theatre, paediatric } \\
\text { anaesthetist } \\
\text { Nentanyl continuous intravenous } \\
\text { infusion, pancuronium, and intubation }\end{array}$ & $\begin{array}{l}\text { Neonal medical unit, neonatologist } \\
\text { (n } 12)\end{array}$ \\
\hline
\end{tabular}

Table 2 Cardiorespiratory stability scoring

\begin{tabular}{|c|c|c|}
\hline Score & Designation & Criteria \\
\hline 0 & Improved from baseline & $\begin{array}{l}\text { Decreased oxygen requirement }(>20 \% \text { relative change } \\
\text { in } \mathrm{FIO}_{2} \text { ) }\end{array}$ \\
\hline 1 & $\begin{array}{l}\text { No change from } \\
\text { baseline }\end{array}$ & \\
\hline 2 & Mild instability & $\begin{array}{l}\text { Increased oxygen requirement }(20-50 \% \text { relative change in } \\
\left.\mathrm{FIO}_{2}\right) \text {, more apnoeas and/or bradycardias responding to } \\
\text { gentle stimulation ( } 100 \% \text { increase or } 5 \text { if none before) }\end{array}$ \\
\hline 3 & Marked instability & $\begin{array}{l}\text { Increased oxygen requirement ( }>50 \% \text { relative change in } \\
\left.\text { FIO }_{2}\right) \text {, more apnoeas and/or bradycardias responding to } \\
\text { vigorous stimulation ( } 100 \% \text { increase or } 5 \text { if none before), } \\
\text { higher ventilation requirement }\end{array}$ \\
\hline 4 & Life threatening event & $\begin{array}{l}\text { Requiring emergency resuscitation (for example, } \\
\text { intubation, suction/bag and mask oxygen, cardiac massage) }\end{array}$ \\
\hline
\end{tabular}

$\mathrm{FIO}_{2}=$ fractional inspired oxygen concentration.

Table 3 Median values (ranges) for gestational age, birth weight, postmenstrual age at treatment, weight at treatment, and duration of treatment

\begin{tabular}{|c|c|c|c|}
\hline & Group $A$ & Group B & Group $C$ \\
\hline Gestational age $^{1}$ (weeks) & $25(24-28)$ & $26(25-30)$ & $25(23-27)$ \\
\hline Birth weight $^{2}(\mathrm{~g})$ & $800(620-990)$ & $780(660-1134)$ & $660(500-1055)$ \\
\hline $\begin{array}{l}\text { Postmenstrual age at } \\
\text { treatment }^{3} \text { (weeks) }\end{array}$ & $35.5(34-40)$ & $37(34-44)$ & $36(34-39)$ \\
\hline Weight at treatment ${ }^{4}(\mathrm{~g})$ & $1390(1097-1730)$ & $1616(1266-2700)$ & $1445(1200-1957)$ \\
\hline $\begin{array}{l}\text { Duration of treatment } \\
\text { (minutes) }\end{array}$ & $48(30-65)$ & $50(40-70)$ & $50(30-65)$ \\
\hline
\end{tabular}

No significant difference between groups. ${ }^{1} \mathrm{p}=0.12,{ }^{2} \mathrm{p}=0.12,{ }^{3} \mathrm{p}=0.19,{ }^{4} \mathrm{p}=0.06,{ }^{5} \mathrm{p}=0.47$, Kruskal-Wallis one way ANOVA.

Table 4 Incidence of bronchopulmonary dysplasia (incid BPD), ventilatory support at the time of treatment (vent support at $R x$ ), duration of artificial ventilation from birth (dura $I P P V)$, and treatment with surfactant (surfactant $R x$ ) and systemic steroid (steroid $R x$ )

\begin{tabular}{|c|c|c|c|c|c|c|}
\hline $\begin{array}{l}\text { Patient } \\
\text { No }\end{array}$ & Group & $\begin{array}{l}\text { Incid } \\
B P D\end{array}$ & $\begin{array}{l}\text { Vent support at } \\
R x\end{array}$ & $\begin{array}{l}\text { Dura IPPV } \\
\text { (days) }\end{array}$ & $\begin{array}{l}\text { Surfactant } \\
R x\end{array}$ & $\begin{array}{l}\text { Steroid } \\
R x\end{array}$ \\
\hline 1 & A & + & HB & 33 & Yes & Yes \\
\hline 2 & A & + & HB & 19 & Yes & No \\
\hline 3 & A & + & HB & 64 & Yes & No \\
\hline 4 & A & + & HB & 39 & Yes & Yes \\
\hline 5 & A & + & HB & 21 & Yes & No \\
\hline 6 & A & + & HB & 16 & Yes & Yes \\
\hline 7 & A & + & Air & 16 & No & Yes \\
\hline 8 & A & + & HB & 30 & Yes & Yes \\
\hline 9 & A & + & $\mathrm{HB}$ & 33 & Yes & Yes \\
\hline 10 & A & + & Air & 75 & Yes & Yes \\
\hline 11 & A & + & HB & 20 & No & Yes \\
\hline 12 & A & - & Air & 17 & Yes & Yes \\
\hline 13 & B & + & HB & 45 & Yes & No \\
\hline 14 & B & - & Air & 14 & No & No \\
\hline 15 & B & + & HB & 46 & Yes & Yes \\
\hline 16 & B & + & HB & 34 & Yes & Yes \\
\hline 17 & B & + & Air & 26 & Yes & No \\
\hline 18 & B & - & Air & 12 & No & No \\
\hline 19 & C & + & HB & 42 & Yes & No \\
\hline 20 & C & + & HB & 47 & Yes & Yes \\
\hline 21 & C & + & HB & 28 & Yes & Yes \\
\hline 22 & C & + & Air & 50 & No & Yes \\
\hline 23 & C & + & HB & 53 & No & No \\
\hline 24 & C & + & IPPV & 127 & Yes & Yes \\
\hline 25 & C & + & IPPV & 143 & No & Yes \\
\hline 26 & C & + & HB & 40 & Yes & Yes \\
\hline 27 & C & + & HB & 54 & Yes & Yes \\
\hline 28 & C & - & Air & 19 & Yes & No \\
\hline 29 & C & + & IPPV & 144 & Yes & No \\
\hline 30 & C & + & $\mathrm{HB}$ & 42 & Yes & Yes \\
\hline
\end{tabular}

$\mathrm{BPD},-=$ absent,$+=$ present $; \mathrm{HB}=$ head box oxygen; $\mathrm{IPPV}=$ intermittent positive pressure ventilation; for surfactant and steroid treatment, Yes $=$ drug administered, no $=$ drug not administered.
The total study population was heterogeneous in terms of infant health. In order to make comparisons of post-treatment systemic stability between groups, we devised a scoring system based upon cardiovascular and respiratory variables. The system was designed to show changes in the overall systemic status of infants on a day to day basis. The details of this cardiorespiratory stability scoring are summarised in Table 2. In our NMU policy an apnoeic episode was defined as being equal to or greater than 20 seconds' duration and a bradycardiac episode was defined as a heart rate of equal to or less than 90 beats per minute. To reverse more significant apnoeic and bradycardiac episodes gentle stimulation (for example, touching a hand) or vigorous stimulation (for example, firmly rubbing a limb) was performed by neonatal staff. The daily oxygen requirement was calculated as the mean of the fractional inspired oxygen concentration $\left(\mathrm{FIO}_{2}\right)$ values recorded for each day. Ventilatory support ranged from, in descending order, intermittent positive pressure ventilation (IPPV), to continuous positive airway pressure ventilation (CPAP), to head box oxygen, to air. Change in ventilation requirement of a baby was defined as a change in the level of ventilatory support-for example, from head box oxygen to CPAP. Scores were calculated for each 24 hour period starting 4 days preoperatively, to provide a baseline, and continuing for 7 days postoperatively. A score of greater than 1 indicates deterioration from baseline status (that is, increased instability) and a score of less than 1 indicates improvement (that is, decreased instability).

Statistical analysis was performed using one way and repeated measures analysis of variance (ANOVA) and Mann-Whitney $U$ tests depending upon which groups of data were being compared. A $p$ value of 0.05 or less was considered significant.

\section{Results}

The study population consisted of 30 babies in which there were 12 babies in group A, six in group $\mathrm{B}$, and 12 in group $\mathrm{C}$. Demographic data are shown in Table 3. No significant group differences were found for gestational age, birth weight, postmenstrual age at treatment, weight at treatment, or duration of treatment. The incidence of bronchopulmonary dysplasia, artificial ventilation at the time of treatment, duration of artificial ventilation, and treatment with surfactant and systemic steroids are shown in Table 4. All except four infants had bronchopulmonary dysplasia (BPD) with active chronic lung disease at the time of treatment. Analysis of duration of IPPV shows a significant difference between the groups $(\mathrm{p}=$ 0.019 , Kruskal-Wallis one way ANOVA). Comparison of the three groups for duration of IPPV using Mann-Whitney U test shows that the difference occurs between groups $\mathrm{A}$ and $\mathrm{C}$.

Two infants had other significant respiratory problems in the perioperative period. One baby in group A (patient no 5) developed pneumonia on the fifth postoperative day and one baby 
Table 5 Cardiorespiratory stability scores for the study population. Details of the changes from baseline cardiorespiratory status which occurred during each 24 hour period are given next to the scores

\begin{tabular}{|c|c|c|c|c|c|c|c|c|c|c|c|c|}
\hline \multirow{2}{*}{$\begin{array}{l}\text { Patient } \\
\text { No }\end{array}$} & \multirow[b]{2}{*}{ Group } & \multicolumn{11}{|c|}{ Time (days) } \\
\hline & & -4 & -3 & -2 & -1 & 1 & 2 & 3 & 4 & 5 & 6 & 7 \\
\hline 1 & A & 1 & 1 & 1 & 1 & $\begin{array}{l}4 \\
\text { Emergency } \\
\text { intubation }\end{array}$ & $3 \mathrm{HB}$ to IPPV & 3 IPPV & 3 IPPV & 2 CPAP & 3 IPPV & $\begin{array}{l}2 \text { Extubated } \\
5 \mathrm{~B} \mathrm{gs}\end{array}$ \\
\hline 2 & A & 1 & 1 & 1 & 1 & $\begin{array}{l}4 \\
\text { Suction bag } \\
\text { and mask }\end{array}$ & $3 \uparrow \mathrm{O}_{2}>50 \%$ & $25 \mathrm{~B}$ gs & $3 \mathrm{HB}$ to IPPV & 3 IPPV & 3 IPPV & $\begin{array}{l}2 \text { Extubated } \\
7 \mathrm{AB} \text { gs }\end{array}$ \\
\hline 3 & A & 1 & 1 & 1 & 1 & $\begin{array}{l}4 \\
\text { Suction bag } \\
\text { and mask }\end{array}$ & $3 \mathrm{HB}$ to IPPV & $\begin{array}{l}3 \mathrm{IPPV} \uparrow \mathrm{O}_{2} \\
>50 \%\end{array}$ & $\begin{array}{l}3 \mathrm{CPAP} 7 \mathrm{AB} \\
\text { vs }\end{array}$ & 3 CPAP & $\begin{array}{l}2 \text { Extubated } \\
6 \mathrm{~B} \mathrm{gs}\end{array}$ & $28 \mathrm{AB}$ gs \\
\hline 4 & A & 1 & 1 & 1 & 1 & $\begin{array}{l}3 \\
\text { Air to IPPV }\end{array}$ & 3 IPPV & 3 IPPV & 3 IPPV & $2 \mathrm{CPAP}$ & $\begin{array}{l}2 \text { Extubated } \\
9 \mathrm{AB} \text { gs }\end{array}$ & 1 \\
\hline 5 & A & 1 & 1 & 1 & 1 & $25 \mathrm{~B}$ gs & $28 \mathrm{~B}$ gs & $27 \mathrm{AB}$ gs & $\begin{array}{l}313 \mathrm{~B} \text { gs } 6 \mathrm{AB} \\
\text { vs }\end{array}$ & $36 \mathrm{~B}$ vs & $211 \mathrm{~B}$ gs & $\begin{array}{l}25 \mathrm{~B} \text { gs } \uparrow \mathrm{O}_{2} \\
>20 \%\end{array}$ \\
\hline 6 & A & 1 & 1 & $\begin{array}{l}2 \uparrow \mathrm{O}_{2} \\
>20 \%\end{array}$ & 1 & $26 \mathrm{~B}$ gs & 1 & $37 \mathrm{AB}$ vs & 1 & $0 \downarrow \mathrm{O}_{2}>20 \%$ & $0 \downarrow \mathrm{O}_{2}>20 \%$ & $0 \downarrow \mathrm{O}_{2}>20 \%$ \\
\hline 7 & A & 1 & 1 & 1 & 1 & $27 \mathrm{~B}$ gs & $2 \uparrow \mathrm{O}_{2}>20 \%$ & 1 & 1 & 1 & 1 & 1 \\
\hline 8 & A & 1 & $26 \mathrm{~B} g \mathrm{~s}$ & 1 & 1 & 1 & $27 \mathrm{AB}$ gs & 1 & $2 \uparrow \mathrm{O}_{2}>20 \%$ & 1 & $\begin{array}{l}315 \mathrm{AB} \text { vs } \\
\text { CPAP }\end{array}$ & 1 \\
\hline 9 & A & 1 & 1 & 1 & 1 & 1 & $2 \uparrow \mathrm{O}_{2}>20 \%$ & 1 & 1 & 1 & 1 & 1 \\
\hline 10 & A & 1 & 1 & 1 & 1 & 1 & 1 & 1 & 1 & 1 & 1 & 1 \\
\hline 11 & A & 1 & 1 & 1 & 1 & 1 & 1 & 1 & 1 & 1 & 1 & 1 \\
\hline 12 & A & 1 & 1 & 1 & 1 & 1 & 1 & 1 & 1 & 1 & 1 & 1 \\
\hline 13 & B & 1 & 1 & 1 & 1 & $\begin{array}{l}3 \text { Elective } \\
\text { IPPV }\end{array}$ & 3 IPPV & 3 IPPV & $\begin{array}{l}2 \text { Extubated } \\
9 \mathrm{AB} \text { gs }\end{array}$ & $212 \mathrm{AB} g s$ & 1 & 1 \\
\hline 14 & B & 1 & 1 & 1 & 1 & $28 \mathrm{~A} \mathrm{gs}$ & 1 & 1 & 1 & 1 & 1 & 1 \\
\hline 15 & B & 1 & 1 & 1 & 1 & 1 & $0 \downarrow \mathrm{O}_{2}>20 \%$ & $0 \downarrow \mathrm{O}_{2}>20 \%$ & $0 \downarrow \mathrm{O}_{2}>20 \%$ & $0 \downarrow \mathrm{O}_{2}>20 \%$ & $0 \downarrow \mathrm{O}_{2}>20 \%$ & $0 \downarrow \mathrm{O}_{2}>20 \%$ \\
\hline 16 & B & 1 & 1 & 1 & 1 & 1 & 1 & 1 & $\begin{array}{l}25 \mathrm{~B} \text { gs } \uparrow \mathrm{O}_{2} \\
>20 \%\end{array}$ & 1 & 1 & 1 \\
\hline 17 & B & 1 & 1 & 1 & 1 & 1 & 1 & 1 & 1 & 1 & 1 & 1 \\
\hline 18 & B & 1 & 1 & 1 & 1 & 1 & 1 & 1 & 1 & 1 & 1 & 1 \\
\hline 19 & C & 1 & 1 & 1 & 1 & $2 \uparrow \mathrm{O}_{2}>20 \%$ & $26 \mathrm{~B} \mathrm{gs}$ & 1 & 1 & 1 & 1 & 1 \\
\hline 20 & $\mathrm{C}$ & 1 & 1 & 1 & 1 & $2 \uparrow \mathrm{O}_{2}>20 \%$ & $25 \mathrm{AB} g \mathrm{~s}$ & 0 & $314 \mathrm{AB}$ vs & $27 \mathrm{AB}$ gs & $\begin{array}{l}211 \mathrm{AB} g \mathrm{gs} \\
\uparrow \mathrm{O}_{2}>20 \%\end{array}$ & 1 \\
\hline 21 & C & 1 & 1 & 1 & 1 & $29 \mathrm{~A} \mathrm{gs}$ & $0 \downarrow \mathrm{O}_{2}>20 \%$ & $0 \downarrow \mathrm{O}_{2}>20 \%$ & 1 & $0 \downarrow \mathrm{O}_{2}>20 \%$ & 1 & 1 \\
\hline 22 & C & 1 & 1 & 1 & 1 & $29 \mathrm{~B} g s$ & 1 & 1 & 1 & 1 & 1 & 1 \\
\hline 23 & C & 1 & 1 & 1 & 1 & $\begin{array}{l}2 \uparrow \mathrm{O}_{2}>20 \% \\
9 \mathrm{AB} \text { gs }\end{array}$ & 1 & 1 & $0 \downarrow \mathrm{O}_{2}>20 \%$ & $0 \downarrow \mathrm{O}_{2}>20 \%$ & $0 \downarrow \mathrm{O}_{2}>20 \%$ & 1 \\
\hline 24 & $\mathrm{C}$ & 1 & 1 & $\begin{array}{l}27 \mathrm{~B} \\
\mathrm{gs}\end{array}$ & 1 & 1 & $\begin{array}{l}0 \text { IPPV to } \\
\text { CPAP }\end{array}$ & 1 & 1 & 1 & 1 & 1 \\
\hline 25 & C & 1 & 1 & 1 & 1 & 1 & 1 & $2 \uparrow \mathrm{O}_{2}>20 \%$ & 1 & 1 & 1 & 1 \\
\hline 26 & C & 1 & 1 & 1 & 1 & 1 & 1 & 1 & 1 & 1 & 1 & 1 \\
\hline 27 & C & 1 & 1 & 1 & 1 & 1 & 1 & 1 & 1 & 1 & 1 & 1 \\
\hline 28 & C & 1 & 1 & 1 & 1 & 1 & 1 & 1 & 1 & 1 & 1 & 1 \\
\hline 29 & $\mathrm{C}$ & 1 & 1 & 1 & 1 & 1 & $0 \downarrow \mathrm{O}_{2}>20 \%$ & 1 & $\begin{array}{l}0 \text { IPPV to } \\
\text { CPAP }\end{array}$ & 1 & 1 & 1 \\
\hline 30 & $\mathrm{C}$ & 1 & 1 & 1 & 1 & $0 \downarrow \mathrm{O}_{2}>20 \%$ & 1 & 1 & $2 \uparrow \mathrm{O}_{2}>20 \%$ & $2 \uparrow \mathrm{O}_{2}>20 \%$ & 1 & 1 \\
\hline
\end{tabular}

Days -4 to -1 are preoperative and days 1 to 7 are postoperative. $\mathrm{HB}=$ head box oxygen; IPPV $=$ intermittent positive pressure ventilation; CPAP $=$ continuous positive airway pressure ventilation; $\mathrm{A}=$ apnoea; $\mathrm{B}=$ bradycardia; $\mathrm{gs}=$ gentle stimulation; vs = vigorous stimulation; $\uparrow=$ increased; $\downarrow=$ decreased; $\mathrm{O}_{2}=$ oxygen .

in group C (patient no 19) had a coexistent chest infection with mucus plugging at the time of treatment.

The cardiorespiratory stability scores and details of the changes from baseline cardiorespiratory status are shown in Table 5. In group A five babies showed mild instability and four babies showed marked instability in the first 48 hours after treatment. Of the four babies showing marked instability, three suffered life threatening events at the time of treatment (patient nos 1-3, Table 5), and all three of these infants required resuscitation. One infant underwent emergency endotracheal intubation followed by IPPV for 4 days. The other two needed airway suction, bag, and mask oxygen and were later intubated requiring IPPV for

Table 6 Mean cardiorespiratory stability scores (taken over each 24 hour period) from 4 days preoperatively ( $(-)$ to 7 days postoperatively

\begin{tabular}{|c|c|c|c|c|c|c|c|c|c|c|c|}
\hline & \multicolumn{11}{|c|}{ Time (days) } \\
\hline & -4 & -3 & -2 & -1 & 1 & 2 & 3 & 4 & 5 & 6 & 7 \\
\hline Group A & 1.00 & 1.08 & 1.08 & 1.00 & 2.17 & 2.00 & 1.83 & 1.92 & 1.58 & 1.67 & 1.25 \\
\hline Group B & 1.00 & 1.00 & 1.00 & 1.00 & 1.50 & 1.17 & 1.17 & 1.17 & 1.00 & 0.83 & 0.83 \\
\hline Group C & 1.00 & 1.00 & 1.08 & 1.00 & 1.33 & 0.92 & 1.00 & 1.08 & 1.00 & 1.00 & 1.00 \\
\hline
\end{tabular}

several days. In these three cases following resuscitation, the cryotherapy procedure was abandoned and necessitated repeat treatment as a result of failure of ROP regression. Ultimately, successful regression of neovascularisation was achieved in all study subjects.

In group $B$ one baby showed mild and one showed marked instability during the first 48 hours after treatment. In group $C$ five babies showed mild instability only, during the first 48 hours after treatment. Five infants in group B were extubated within the first 24 hours after surgery. One infant in group B (patient no 13, Table 5) was maintained on IPPV for 3 days following elective intubation at the time of surgery. Eleven infants in group $\mathrm{C}$ were extubated within the first 24 hours and one (patient no 19, Table 5) was extubated 40 hours after surgery. In babies in groups B and C postoperative systemic instability was noted to occur after extubation, typically lasting for several hours. No life threatening events were encountered in babies from groups B or C.

The mean cardiorespiratory stability scores pre- and postoperatively (Table 6) were plotted for each day (Fig 1). The graph obtained indicates good baseline stability for the 4 days 


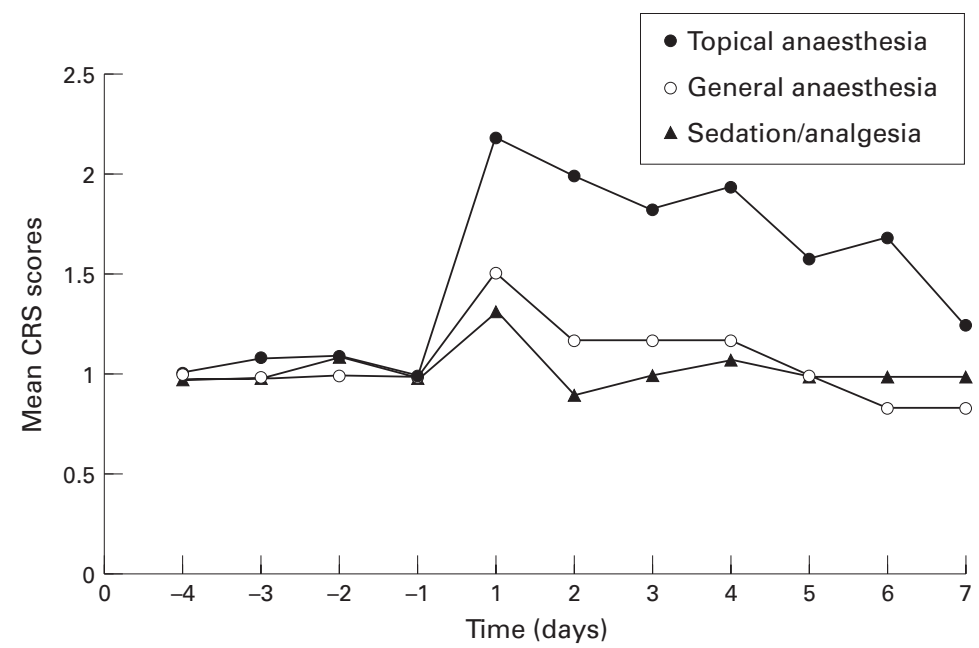

Figure 1 Mean cardiorespiratory stability (CRS) scores from 4 days preoperatively (-) to 7 days postoperatively. Scores above 1 indicate deterioration from baseline status (that is, increased instability) and scores below 1 indicate improvement (that is, decreased instability).
ROP treatment, systemic complications usually occurred soon after starting cryotherapy and this has been reported by others. ${ }^{10}$ All babies received similar postoperative analgesia and eyedrops.

Search for perioperative confounding factors, which may have resulted in increased cardiorespiratory instability unrelated to the ROP treatment, revealed only one case of respiratory infection in the week following surgery in each of groups A and C. All three groups had a high incidence of bronchopulmonary dysplasia (BPD), but there is a trend (NS) towards more severe BPD in group C; patients 24, 25, and 29 requiring artificial ventilation for very prolonged periods since birth. However, contrary to expectation group $\mathrm{C}$ had a significantly better outcome. The three groups were comparable in terms of treatment with surfactant and systemic steroids. The severe BPD in the three infants, which required prolonged artificial ventilation, probably reflects their extreme prematurity and low birth weight rather than specific differences in treatment.

Our results indicate that cardiac and respiratory adverse events are more common using topical anaesthesia. More importantly, life threatening events during treatment were encountered only in the topical anaesthesia group. In each instance when resuscitation was required, the cryotherapy was abandoned to allow recovery and stabilisation of the infant, with potentially serious implications in terms of arresting progression of sight threatening retinopathy. The three babies suffering these serious episodes needed to undergo a further cryotherapy procedure several days later. Following repeat treatment satisfactory neovascular regression was achieved. Otherwise no ocular complications were encountered that could be attributable to variation in anaesthetic support.

Episodes of bradycardia did occur during cryotherapy in groups B and C, but these were of short duration and none required resuscitative measures. Control of the airway and assisted ventilation in groups B and C were other factors in achieving this increased stability during treatment. Group A provided the worst scenario when respiratory arrest had occurred; the anaesthetist in attendance having to gain control of the airway and assist ventilation very rapidly to prevent profound hypoxia. If laryngospasm occurs during resuscitation, the situation becomes extremely hazardous and significantly increases the risk of infant death. Elective intubation, employed in groups B and C, can be performed safely after preoxygenation of the baby.

Several investigators have described systemic instability of preterm infants in the early postoperative period, concentrating attention on the first 24 hours after surgery. ${ }^{13}{ }^{14}$ Our results indicate that instability after treatment may be much more prolonged in some babies. Four babies in group A were unstable for 7 days postoperatively. In contrast, most babies in groups B and C had returned to pretreatment gestational age, birth weight, postmenstrual age at treatment, and duration of surgery. In those babies showing instability at the time of 
baseline cardiorespiratory status by day 2 , and indeed some showed improvement from baseline.

We have attributed the differences in degree and duration of instability between the three groups largely to the stress of the cryotherapy procedure itself, where significant differences in outcome appear to relate to the type of anaesthesia employed. Every effort should be made to avoid protracted systemic instability, since there is evidence that recurrent or prolonged apnoeic episodes may result in permanent neuronal damage and consequent impaired neurological development. ${ }^{15} 16$

Cryotherapy is a painful procedure and adequate analgesia is essential. Fentanyl, an opioid analgesic, is effective in suppressing the stress response to surgery ${ }^{4}$ and this drug has been used widely in neonatal anaesthesia. ${ }^{17-20}$ The half life of fentanyl is shorter than morphine, but if necessary any effects of respiratory depression can readily be reversed with intravenous naloxone. Inhalational general anaesthesia provides analgesia and reduces the stress response, ${ }^{5}$ and a further reduction in the stress response has been demonstrated by adding fentanyl to the anaesthetic regimen. ${ }^{4}$ It is unlikely that topical anaesthesia alone provides sufficient analgesia to suppress the stress response to cryotherapy. The preferred method of providing analgesia for ROP treatment has not been determined, and clearly it is an area worthy of further study.

Although the safety of the infant is paramount, a further consideration is that of achieving optimal conditions for the surgeon to apply treatment. Retinal ablation for ROP can be a difficult technique, made easier if the baby is still. Under suitable conditions treatment application should be quicker and more accurate. Both general anaesthesia and sedation with muscle relaxation provide these conditions.

In many centres where laser is increasingly employed in preference to cryotherapy the latter is still used, either as 'backup' or when laser proves difficult because of miosed pupils. Laser application also has potential to induce stress when scleral indentation is necessary or in cases of inadvertent deeper retinal and pupil margin burns in eyes with rigid, poorly dilated pupils. Unwanted ocular movement increases the risk of visual damage due to accidental treatment of posterior retina. Hence, in many cases, some form of anaesthetic support remains desirable with laser use.

Finally, there are other considerations when providing a service for the treatment of ROP. In some units a specialised paediatric anaesthetic service may not be readily available or may be based in another hospital necessitating transfer of babies needing treatment. Use of topical anaesthesia is a simple approach, although in our practice a paediatric anaesthetist was still required to remain in attendance during treatment. In our hospital the sedation/ analgesia technique used in group $\mathrm{C}$ is carried out in the NMU in a dedicated treatment room. Intubation and administration of drugs are performed by a neonatologist, and we and others ${ }^{21}$ have found this approach works well. In the neonatal intensive care unit there is ready access to all emergency support and the complications associated with transportation are eliminated.

In conclusion, use of topical anaesthesia alone for the treatment of ROP is associated with more severe cardiorespiratory complications during and after surgery. The systemic instability following cryotherapy with topical anaesthesia is more protracted than with general anaesthesia or sedation/analgesia. The study by Schulenburg and Bloom ${ }^{12}$ indicates that, currently, up to $43 \%$ of units in the UK may be employing local anaesthesia in the treatment of ROP.

The authors thank Mr Alan Ridgway, Royal Eye Hospital, Manchester, Drs D Sims, A Emmerson, and S Byrne, Regional Neonatal Medical Unit, St Mary's Hospital, Manchester for
invaluable discussion, and Dr V Hillier, senior statistician, Manchester University Medical School for statistical advice.

1 Anand KJS, Hickey PR. Pain and its effects in the human neonate and fetus. N Engl f Med 1987;317:1321-9.

2 Pokela ML. Pain relief can reduce hypoxaemia in distressed neonates during routine treatment procedures. Pediatrics 1994;93:379-83.

3 Hickey PR, Hansen DD, Wessel DL, Lang P, Jonas RA, Elixson EM. Blunting of stress responses in the pulmonary circulation of infants by fentanyl. Anesth Analg 1985;64: 1137-42.

4 Anand KJS, Sippel WG, Aynsley-Green A. Randomised trial of fentanyl anaesthesia in preterm babies undergoing surgery: effects on the stress response. Lancet 1987;i:2438.

5 Anand KJS, Sippel WG, Schofield NM, Aynsley-Green A. Does halothane anaesthesia decrease the metabolic and endocrine stress responses of newborn infants undergoing endocrine stress responses of newb

6 Gregory GA, Steward DJ. Life-threatening perioperative apnea in the ex-'premie'. Anaesthesiology 1983;59:495-8

7 Tay-Uyboco JS, Kwiatkowski K, Cates DB, Kavanagh L, Rigatto $\mathrm{H}$. Hypoxic airway constriction in infants of very low birth weight recovering from moderate to severe bronchopulmonary dysplasia. F Pediatr 1989;115:456-9.

8 Clarke WN, Hodges E, Noel LP, Roberts D, Coneys M. The oculocardiac reflex during ophthalmoscopy in premature infants. Am f Ophthalmol 1985;99:649-51.

9 Cryotherapy for Retinopathy of Prematurity Cooperative Group. Multicenter trial of cryotherapy for retinopathy of prematurity: preliminary results. Arch Ophthalmol 1988; 106:471-9.

10 Brown GC, Tasman WS, Naidoff M, Schaffer DB, Quinn G, Bhutani VK. Systemic complications associated with retinal cryoablation for retinopathy of prematurity. Ophthalmology 1990;97:855-8.

11 Dhillon B, Laing WI, Fleck B. Cryotherapy for retinopathy of prematurity in a regional neonatal intensive care unit. $\mathcal{f}$ R Coll Surg Edinb 1992;37:83-8.

12 Schulenburg WE, Bloom PA. Current problems in the management of ROP. Acta Ophthalmol Scand 1995;73 (suppl 214): S14-6.

13 Welborn LG, Hannallah RS, Fink R, Ruttiman UE, Hicks $M$. High-dose caffeine suppresses postoperative apnea in former preterm infants. Anaesthesiology 1989;71:347-9.

14 Welborn LG, Rice LJ, Hannallah RS, Broadman LM, Ruttiman UE, Fink R. Postoperative apnea in former preterm infants: prospective comparison of spinal and general anaesthesia. Anaesthesiology 1990;72:838-42.

15 Sinha SK, Davies JM, Sims DG, Chiswick ML. Relation between periventricular haemorrhage and ischaemic brain lesions diagnosed by ultrasound in very pre-term infants. Lancet $1985 ; \mathbf{i i}: 1154-5$.

16 Butcher-Puech MC, Henderson-Smart DJ, Holley D, Lacey JL, Edwards DA. Relation between apnoea duration and type and neurological status of preterm infants. Arch Dis type and neurological
Child 1985;60:953-8.

17 Robinson S, Gregory GA. Fentanyl-air-oxygen anaesthesia for ligation of patent ductus arteriosus in preterm infants. Anesth Analg 1981;60:331-4

18 Collins C, Koren G, Crean P, Klein J, Roy WL, MacLeod SM. Fentanyl pharmacokinetics and hemodynamic effects in preterm infants during ligation of patent ductus arteriosus. Anesth Analg 1985;64:1078-80.

19 Yaster $M$. The dose response of fentanyl in neonatal anaesthesia. Anaesthesiology 1987;66:433-5.

20 Roth B, Schlunder C, Houben F, Gunther M, Theisohn M. Analgesia and sedation in neonatal intensive care using 17:121-7.

21 Clark DI, O'Brien C, Weindling AM, Saeed M. Initial experience of screening for retinopathy of prematurity. Arch Dis Child 1992;67:1233-6. 